\title{
Maternal conjugated linoleic acid modulates TAG metabolism in adult rat offspring
}

\author{
Jimena Lavandera ${ }^{1,2}$, Carolina D. Gerstner ${ }^{1,2}$, Juliana Saín ${ }^{1,2}$, Ana C. Fariña ${ }^{1}$, Marcela A. González ${ }^{1}$ and \\ Claudio A. Bernal ${ }^{1,2 *}$ \\ ${ }^{1}$ Cátedra de Bromatología y Nutrición, Facultad de Bioquímica y Ciencias Biológicas, Universidad Nacional del Litoral, \\ Ciudad Universitaria, Paraje el Pozo S/N, C.C. 242 (C.P. 3000), Santa Fe, Argentina \\ ${ }^{2}$ Consejo Nacional de Investigaciones Científicas y Técnicas (CONICET), Colectora Ruta Nacional 168 Km O, "Predio CONICET \\ Dr. Alberto Cassano" (C.P. 3000), Santa Fe, Argentina
}

(Submitted 26 June 2017 - Final revision received 19 September 2017 - Accepted 2 October 2017)

\section{Abstract}

Conjugated linoleic acid (CLA) might regulate the lipid depots in liver and adipose tissue. As there is an association between maternal nutrition, fat depots and risk of offspring chronic disease, the aim was to investigate the effect of maternal CLA consumption on TAG regulation and some inflammatory parameters in adult male rat offspring receiving or not receiving CLA. Female Wistar rats were fed control (C) or CLA-supplemented ( $1 \%, \mathrm{w} / \mathrm{w})$ diets during 4 weeks before and throughout pregnancy and lactation. After weaning, male offspring of CLA rats were fed C or CLA diets (CLA/C and CLA/CLA groups, respectively), whereas C male rat offspring were fed a C diet (C/C group) for 9 weeks. Serum TAG levels were increased in the CLA/CLA and CLA/C groups, associated with a reduction of lipoprotein lipase activity and weights of adipose tissue. The liver TAG levels were decreased in the CLA/CLA group, related to a significant reduction of fatty acid synthase (FAS), acetyl-CoA carboxylase (ACC) and glucose-6-phosphate dehydrogenase enzyme activities, as well as to the mRNA levels of FAS, ACC, stearoyl-CoA desaturase-1 and sterol regulatory element-binding protein-1c. Even though normal TAG levels were found in the liver of CLA/C rats, a reduction of lipogenesis was also observed. Thus, these results demonstrated a programming effect of CLA on the lipid metabolic pathways leading to a preventive effect on the TAG accretion in adipose tissue and the liver of male rat offspring. This knowledge could be important to develop some dietary strategies leading to a reduced incidence of obesity and fatty acid liver disease in humans.

\section{Key words: Conjugated linoleic acid: Maternal programming: Offsprings: Lipid metabolism: TAG}

Conjugated linoleic acid (CLA) refers to a group of dienoic derivatives of linoleic acid with conjugated double bonds arranged in different combinations of cis and trans configuration $^{(1)}$. The bioactive properties of $c 9 t 11$-CLA and $t 10 c 12-C L A$ isomers have been extensively studied. CLA is incorporated into tissues $^{(2)}$, increases energy expenditure, modulates TAG metabolism in liver, adipose tissue and skeletal muscle, modifies inflammatory markers and regulates oxidative status ${ }^{(3,4)}$. Studies in different experimental animal models have shown controversial results on hepatic TAG content. CLA might attenuate or prevent the development of hepatic steatosis in rats ${ }^{(5,6)}$, whereas a lipoatrophic effect, characterised by a severe reduction of adipose tissue, elevated fat accretion in the liver and hepatomegaly has been described in mice ${ }^{(7)}$. The differential CLA response on TAG metabolism depends on the type of isomers, the level of CLA and fat in the diets and species ${ }^{(8)}$, among other factors.
The relationship between the intra-uterine environment and the propensity to lipid metabolic alterations in adult life was first noted in response to maternal food restriction ${ }^{(9)}$. Similarly, maternal high-fat diet consumption was associated with metabolic disorders including obesity ${ }^{(10)}$, hepatic steatosis ${ }^{(11)}$, glucose intolerance and inflammation in later life ${ }^{(12)}$. Even though the type and amount of the maternal diet is very important, maternal body fat accumulation during early pregnancy plays a determining role in fetus development and propension or prevention of metabolic alterations in adult life ${ }^{(13)}$. There is limited information about the effects of compounds or agents, such as CLA, that by regulating body fat accretion could modulate the lipid metabolism in offspring animals. In this sense, maternal CLA supplementation in rats fed high-fat diets reverted some negative effects on inflammation, glucose intolerance, insulin insensitivity, hyperlipidaemia and other associated metabolic disorders $^{(14-16)}$ in offspring. Moreover, we have previously

Abbreviations: ACC, Acetyl-CoA carboxylase; C, control; CLA, conjugated linoleic acid; CPT-Ia, carnitine palmitoyltransferase Ia; EWAT, epididymal white adipose tissue; FA, fatty acids; FAME, fatty acid methyl esters; FAS, fatty acid synthase; G6PDH, glucose-6 phosphate dehydrogenase; LPL, lipoprotein lipase; SCD-1, stearoyl-CoA desaturase-1; SREBP-1c, sterol regulatory element-binding protein-1c; TAG-SR, TAG secretion rate.

* Corresponding author: C. A. Bernal, fax +54342 457 5221, email cbernal@fbcb.unl.edu.ar 
shown ${ }^{(17)}$ that mice fed high-fat diets increased fetal resorption, decreased the IL- 4 placental gene expression in the first generation and increased the TNF $\alpha$ gene expression in the second generation. In this generation, CLA normalised Tnf $\alpha$ decreased Il4 and transforming growth factor $\beta 1$. Nevertheless, at least to the best of our knowledge, there is no information on the metabolic effects of CLA at recommended fat levels. Therefore, the aim of this study was to investigate the effect of maternal CLA consumption on TAG regulation and some inflammatory parameters related with TAG accretion in adult male rat offspring receiving or not receiving CLA.

\section{Methods}

\section{Materials and diets}

Nutrients and other chemical compounds, vitamins and minerals for the preparation of the diets, were of chemical grade or better, with the exception of soyabean oil (Cada Día), sucrose, cellulose and maize starch, which were obtained from local sources. CLA-mix oil was obtained from Lipid Nutrition B.V. and consisted of an equimolecular mixture of c9t11-CLA and $t 10 c 12-C L A$. All solvents and reagents used for the fatty acid (FA) quantification were of chromatography grade purchased from Merck. Internal standard glyceryl tritridecanoate (13:0-TAG) and external standards GLC-463 containing fifty-two fatty acids methyl esters (FAME) mixture (purity $>99 \%$ ) were purchased from Nu-Chek. CLA, cis/trans mix (catalogue no. 05507), was purchased from Sigma. Other FAME standards were provided by the International CYTED Net (208RT0343). Primers used for PCR analysis were synthesised by Invitrogen. For the enzyme assays, the materials were from Sigma. All the other chemicals and reagents used were at least American Chemical Society degree or molecular grade and purchased from Merck, Invitrogen and Applied Biosystems. The TAG test kit was obtained from the Sociedad de Bioquímicos. For all the experiments, two isoenergetic diets (Table 1) containing $7 \%(\mathrm{w} / \mathrm{w})$ of different

Table 1. Composition of the experimental diets

\begin{tabular}{|c|c|c|}
\hline $\mathrm{g} / \mathrm{kg}$ dry diet & $\mathrm{C}^{*}$ & $\mathrm{CLA}^{*}$ \\
\hline Soyabean oil & $70 \cdot 0$ & $60 \cdot$ \\
\hline CLA-mix oil & - & $10 \cdot 0$ \\
\hline Casein & $200 \cdot 0$ & $200 \cdot 0$ \\
\hline Maize starch & 529.5 & 529.5 \\
\hline Sucrose & $100 \cdot 0$ & $100 \cdot 0$ \\
\hline Fibre & $50 \cdot 0$ & $50 \cdot 0$ \\
\hline Vitamin mixture $†$ & $10 \cdot 0$ & $10 \cdot 0$ \\
\hline Mineral mixture & $35 \cdot 0$ & $35 \cdot 0$ \\
\hline L-Cys, L-Met & 3.0 & 3 \\
\hline Choline & 2.5 & \\
\hline
\end{tabular}

C, control diet; CLA, conjugated linoleic acid diet.

* Homemade prepared based on the American Institute of Nutrition Ad-Hoc Committee recommendation (AIN-93G) formulated for growth, pregnancy and lactation phases of rodents ${ }^{(18)}$

† Vitamin mixture ( per $\mathrm{kg}$ of diet): nicotinic acid, $30.0 \mathrm{mg}$; pantothenate, $15.0 \mathrm{mg}$ pyridoxine, $6.0 \mathrm{mg}$; thiamin, $5.0 \mathrm{mg}$; riboflavin, $6.0 \mathrm{mg}$; folic acid, $2.0 \mathrm{mg}$; vitamin $\mathrm{K}$ $750.0 \mu \mathrm{g}$; D-biotin, $200.0 \mu \mathrm{g}$; vitamin $B_{12}, 24.0 \mu \mathrm{g}$; retinyl acetate, $1.2 \mathrm{mg}$; cholecalciferol, $0.025 \mathrm{mg}$; DL-a-tocopheryl acetate, $50 \mathrm{mg}$.

¥ Mineral mixture (mg/kg of diet): Ca, 5000.0; P, 1561.0; K, 3600.0; S, 300.0 $\mathrm{Na}$ 1019.0; Cl, 1571.0; Mg, 507.0; Fe, 35.0; Zn, 30.0; Mn, 10.0; Cu, 6.0; iodine, 0.2 Mo 0.15; Se, 0.15; Si, 5.0; Cr 1.0; F, 1.0; Ni, 0.5; B, 0.5; Li, 0.1; and V, 0.1. dietary fats were used. The control (C) diet was based on the American Institute of Nutrition Ad-Hoc Committee recommendation (AIN-93G) formulated for growth, pregnancy and lactation phases of rodents ${ }^{(18)}$ and contained $7 \%$ of soyabean oil as source of fats. The CLA diet was identical to the C diet, with the exception that $1 \%(\mathrm{w} / \mathrm{w})$ of the CLA-mix oil replaced $1 \%(\mathrm{w} / \mathrm{w})$ of the soyabean oil. The FA composition of CLA-mix oil (of total FAME) was as follows: 16:0, 5.85\%; 18:0, 1.20\%; c9-18:1, 9.05\%; $c 11-18: 1, \quad 0.41 \%, \quad c 9 t 11-C L A, \quad 38.99 \% ; \quad t 10 c 12-C L A$, $38.76 \%, c 9, c 12-18: 2,1.08 \%$; and other FA, $4.66 \%$. The FA composition of diets (Table 2) was determined by GC as indicated below. The diets were freshly prepared every $3 \mathrm{~d}$, gassed with $\mathrm{N}$ and stored at $0-4^{\circ} \mathrm{C}$.

\section{Animals and experimental design}

All the experiments were conducted in compliance with the regulations of the School of Biochemistry (Universidad Nacional del Litoral) and Guide to the Care and Use of Experimental Animals of Laboratory ${ }^{(19)}$. Male and virgin mature female Wistar rats were provided from the facilities at our University. The animals were housed in collective cages under controlled conditions $\left(23 \pm 2{ }^{\circ} \mathrm{C}\right.$ and $12 \mathrm{~h}$ light $-12 \mathrm{~h}$ dark $)$ and free access to standard food and water. After 1 week of adaptation period, the female rats were randomly divided into two groups ( $n$ 6/ group) and fed C or CLA diets (initial weights: $274 \cdot 1$ (SEм 8.6) and 269.9 (SEM 5.7) g, respectively) for 4 weeks before mating and throughout pregnancy and lactation. At parturition time, litter size was standardised to eight pups per dam in both C- and CLA-fed mothers. The pups were maintained with their own mothers until weaning. In all, twelve post-weaning male pups were randomly selected from $\mathrm{C}$-fed mothers and received the same diet (C/C group). A total of twenty-four post-weaning male pups from CLA-fed mothers were randomly divided into two subgroups. One subgroup of twelve pups was fed the CLA diet (CLA/CLA group) and the other subgroup of twelve pups was fed the $\mathrm{C}$ diet (CLA/C group). The animals from the $\mathrm{C} / \mathrm{C}$, CLA/C and CLA/CLA groups were fed the respective diets for 9 weeks.

After the dietary treatment, one set of 6 animals per group was fasted overnight and killed (09.00-11.00 hours) under

Table 2. Fatty acid composition of experimental diets

\begin{tabular}{lcr}
\hline Fatty acids (\% of total fatty acids methyl esters) & C & CLA \\
\hline $16: 0$ & $10 \cdot 84$ & $10 \cdot 12$ \\
$18: 0$ & $4 \cdot 50$ & $4 \cdot 01$ \\
$c 9-18: 1$ & $17 \cdot 60$ & $16 \cdot 27$ \\
$c 11-18: 1$ & $4 \cdot 10$ & 3.56 \\
$c 9 c 12-18: 2$ & $54 \cdot 30$ & $46 \cdot 53$ \\
$c 6 c 9 c 12-18: 3$ & $0 \cdot 31$ & $0 \cdot 26$ \\
$c 5-20: 1$ & $0 \cdot 16$ & $0 \cdot 13$ \\
$c 9 c 12 c 15-18: 3$ & $7 \cdot 42$ & $6 \cdot 36$ \\
$c 11-20: 1$ & $0 \cdot 14$ & $0 \cdot 12$ \\
$c 9 t 11-C L A$ & $N D$ & $5 \cdot 57$ \\
$t 10 c 12-C L A$ & $N D$ & $5 \cdot 53$ \\
$c 9 c 12 c 15-20: 3$ & 0.39 & 0.33 \\
$24: 0$ & $0 \cdot 11$ & 0.09 \\
$\mathrm{NI}$ & $0 \cdot 13$ & $1 \cdot 12$ \\
\hline
\end{tabular}

C, control diet; CLA, conjugated linoleic acid diet; ND, not detected; NI, not identified. 
anaesthesia (1 mg azepromazine $+100 \mathrm{mg}$ ketamine $/ \mathrm{kg}$ body weight) by cardiac exsanguination. Blood was collected and serum was obtained after centrifugation $\left(1000 \mathrm{~g}\right.$ for $10 \mathrm{~min}$ at $\left.4^{\circ} \mathrm{C}\right)$. Liver, gastrocnemius muscle (GM) and epididymal white adipose tissue (EWAT) were dissected, weighed and immediately frozen. All samples were stored at $-80^{\circ} \mathrm{C}$ until analysis.

\section{Fatty acid composition in liver, epididymal white adipose tissue, serum and dietary lipids}

The CLA levels in liver, EWAT and serum, and the FA composition of experimental diets, were determined by GC using a Shimadzu (GC 2014) chromatograph equipped with a flame ionisation detector. Analyses were carried out with a capillary column CP Sil 88 ( $100 \mathrm{~m}, 0 \cdot 25 \mu \mathrm{m}$ film thickness; Varian). The carrier gas was $\mathrm{H}_{2}$ with a split ratio of $1: 10$. The column temperature was held at $75^{\circ} \mathrm{C}$ for $2 \mathrm{~min}$ after injection, and then $5^{\circ} \mathrm{C} / \mathrm{min}$ to $170^{\circ} \mathrm{C}$, held for $40 \mathrm{~min}, 5^{\circ} \mathrm{C} / \mathrm{min}$ to $220^{\circ} \mathrm{C}$ and held for $40 \mathrm{~min}$. Injection volume was $0.5 \mu \mathrm{l}$ and the column flow was $0.8 \mathrm{ml} / \mathrm{min}$. Total fat in tissues, serum and diets was extracted using the method described by Bligh \& Dyer ${ }^{(20)}$. The FAME were formed by transesterification with methanolic potassium hydroxide solution as an interim stage before saponification (ISO 5509: 2000, Point 5 International Union of Pure and Applied Biochemistry method 2.301). The FAME were identified by comparison of their retention times relative to those of commercial standards. Values of FA content were expressed as percentage of total FA. Further GC details could be obtained from previous publications ${ }^{(21,22)}$

\section{TAG levels in serum and liver}

TAG levels in serum were determined by spectrophotometric methods using a commercially available test kit. Portions of frozen tissue were powdered and homogenised in saline solution $(10 \%, \mathrm{w} / \mathrm{v})$ for TAG determination ${ }^{(23)}$.

\section{Lipoprotein lipase activity in epididymal white adipose tissue and gastrocnemius muscle}

The adipose tissue lipoprotein lipase (LPL) enzyme activity was quantified in EWAT acetone powder by the fluorometric method of Del Prado ${ }^{(24)}$. To assess muscle LPL activity, GM samples were homogenised in a $\mathrm{NH}_{4} \mathrm{Cl} / \mathrm{NH}_{4} \mathrm{OH}$-Heparin buffer and the LPL activity quantification was performed by the technique of Del Prado ${ }^{(24)}$. Values were expressed as nmol fluorescein/min per total tissue or as nmol fluorescein/min per $\mathrm{g}$ tissue. Further methodological details about the assessment have been previously published ${ }^{(22)}$

\section{Lipogenic and $\beta$-oxidative enzyme activities}

In liver homogenates, acetyl-CoA carboxylase (ACC; EC 6.4.1.2), fatty acid synthase (FAS; EC 2.3.1.85) and glucose-6-phosphate dehydrogenase (G6PDH; EC 1.1.1.49) activities, as lipogenic enzymes, were measured according to the methods of Zimmerman $^{(25)}$ Lynen $^{(26)}$ and Kuby \& Noltmann ${ }^{(27)}$, respectively.
The enzyme activities were expressed either as $\mathrm{mU} / \mathrm{mg}$ of protein, where $1 \mathrm{mU}$ was $1 \mathrm{nmol} \mathrm{NADH}$ consumed (ACC), $1 \mathrm{nmol}$ NADPH consumed (FAS) or $1 \mathrm{nmol}$ NADPH produced $(G 6 P D H)$ per min. Carnitine palmitoyltransferase Ia (CPT-Ia; EC 1.3.99.3) activity, as $\beta$-oxidative enzyme, was assessed in the liver mitochondrial fraction by the method described by Bieber et $a l^{(28)}$ and expressed as $\mathrm{mU} / \mathrm{mg}$ of protein $(1 \mathrm{mU}=1 \mathrm{nmol}$ $\mathrm{CoA} / \mathrm{min}$ ). Protein content was determined using bovine serum albumin as standard by the Lowry method ${ }^{(29)}$.

\section{Hepatic mRNA levels of lipogenic and $\beta$-oxidative enzymes, transcriptional factors and inflammatory cytokines}

Total RNA was isolated from liver using Trizol according to the manufacturer's instructions. RNA samples were then treated with a DNA-free kit (Applied Biosystems) to remove any contamination with genomic DNA. The yield and quality of the RNA were assessed by measuring absorbance at 260, 270, 280 and $310 \mathrm{~nm}$ and by electrophoresis on $1.3 \%$ agarose gels. A measure of $1.0 \mu \mathrm{g}$ of total RNA of each sample was reversetranscribed to first-strand complementary DNA (cDNA) using a M-MLV RT. Relative mRNA levels were quantified using realtime PCR with a StepOne 18 TM Real-Time PCR Detection System (Applied Biosystems). Sequence-specific primers were used (Genbank: ACC, NM_022193.1; FAS, NM_017332.1; sterol regulatory element-binding protein-1c (SREBP-1c), NM_0012 76708.1; stearoyl-CoA desaturase-1a (SCD-1a), NM_139192.2; CPT-Ia, NM_031559.2; PPAR $\alpha$, NM_013196.1; IL-6, NM_ 012589.2; IL-1 $\beta$, NM_031512.2; PPAR $\gamma$, NM_013124.3; $\beta$-actin, NM_031144.3; ubiquitin C (UBC), NM_017314.1 and hypoxanthine phosphoribosyltransferase 1 (HPRT1), NM_012583.2), commercially synthesised (Invitrogen Custom Primers) and the sequences were as follows: ACC: 5'-AAC AGT GTA CAG CAT CGC CA-3' (forward), 5'-CAT GCC GTA GTAG GTT GAG GT-3' (reverse); FAS, 5'-CAG AAC TCT TCC AGG ATAG TCA ACA -3' (forward), 5'- GTC GCC CTAG TCA AGG TTC AG -3' (reverse); SREBP-1c, 5'-GGA GCC ATAG GAT TAGC ACA TT-3' (forward), 5'-GCT TCC AGA GAG GAG CCC AG-3' (reverse); SCD-1, 5'-CAC ACG CCG ACC CTC ACA ACT-3' (forward), 5'-TCC GCC CTT CTC TTT GAC AGC C-3' (reverse); CPT1, 5'- ACG TAGA GTAG ACT GGT GGG AAG AAT-3' (forward), 5'-TCT CCA TAGG CGT AGT AGT TAGC TAGT-3' (reverse); PPAR $\alpha, 5$ '-CCC CAC TTAG AAG CAG ATAG ACC-3' (forward), 5'-CCC TAA GTA CTAG GTA GTC CGC-3' (reverse); IL-6, 5'-CCT TCT TAGG GAC TAGA TAGT TAGT TAGA C-3' (forward), 5'- GGG TAGG TAT CCT CTAG TAGA AGT CTC C-3' (reverse); IL-1 $\beta$, 5'-AGG CAG TAGT CAC TCA TTAG TAGG C-3' (forward), 5'- TCA CAT GGG TCA GAC AGC ACG-3' (reverse); PPAR $\gamma$, 5'-CGG AGT CCT CCC AGC TAGT TCG CC-3' (forward), 5'- GGC TCA TAT CTAG TCT CCG TCT TC-3' (reverse); $\beta$-actin 5'-CAT GAA GAT CAA GAT CAT TAGC TCC T-3' (forward), 5'-CTAG CTT GCT GAT CCA CAT CTAG-3' (reverse); UBC 5'- ACACCAAGAAGGTCAAACAGGA-3' (forward), 5'-CA CCTCCCCATCAAACCCAA-3' (reverse); HPRT1 5'-TCCTCCTCA GACCGCTT TTC-3' (forward), 5'-ATCACTAATCACGACGCT GGG-3' (reverse). Standard curves for each primer were generated on separate runs using several serial dilutions 
(1/10-1/1000) of pooled cDNA samples. The corresponding primer efficiency $(\mathrm{E})$ of one cycle in the exponential phase was calculated according to equation $E=10^{(-1 / \text { slope)(30) }}$. All the efficiencies of the primers were 100 (SEM 10)\%. Target genes were normalised with the geometric mean of three housekeeping genes: $\beta$-actin, UBC and HPRT1 ${ }^{(31)}$. Relative expression ratios were calculated using the recommended $2^{-\Delta \Delta C_{t}} \operatorname{method}^{(32)}$.

\section{Hepatic TAG secretion rate}

Another set of six animals per group was used; the animals were fasted overnight and anaesthetised as mentioned above. Then, $600 \mathrm{mg} / \mathrm{kg}$ body weight of triton WR 1339 in saline solution, an agent known to inhibit the peripheral removal of TAG-rich lipoproteins, was injected intravenously ${ }^{(33)}$. Blood samples were taken immediately before and $120 \mathrm{~min}$ after the injection of the triton solution for the estimation of TAG accumulation in serum. Hepatic TAG secretion rate (TAG-SR) was estimated based on serum TAG concentration at 0 and $120 \mathrm{~min}$, plasma volume and body weight. Further details have been previously reported ${ }^{(34)}$.

\section{Statistical analysis}

Values were expressed as means with their standard errors of six animals per group. The minimum sample size needed to detect a statistically significant difference $(P<0.05)$ was calculated $^{(35)}$. A sample size of six had an $80 \%$ power $(P=0.05)$. The statistical analysis was performed by one-way ANOVA $(1 \times 3)$ followed by Scheffe's test $(P<0.05)$, using SPSS version 17.0 (SPSS Inc.), except for the comparison between CLA isomers shown in Table 4 for which Student's $t$ test was used. All post hoc multiple comparisons were made using Tukey's critical range test. Significant differences were considered at $P<0.05$.

\section{Results}

\section{Nutritional parameters and TAG content in serum and liver}

During all the experiment in dams and offspring, the diets were well accepted and the animals showed a healthy status without any pathological manifestation owing to the treatments received. The body weights $(\mathrm{g})$ of dams after 4 weeks of dietary treatment before mating were C: $357 \cdot 2$ (SEM 14.3) and CLA: $347 \cdot 4$ (SEM 15.7) and the mean food intakes $(\mathrm{kJ} / \mathrm{d}$ ) were C: 255.9 (SEM 12.0) and CLA: $253 \cdot 3$ (SEM 5.8). Body and tissue weights of offspring and serum and liver TAG content are shown in Table 3. The final body weights decreased in groups CLA/CLA and CLA/C, parallel to a significant decrease in the EWAT weights. The absolute liver weight was lower in the CLA/CLA and CLA/C groups, but their relative weights were not affected by the dietary treatments. Serum TAG levels were increased in the CLA/CLA and CLA/C groups, and liver TAG levels were decreased in the CLA/CLA group, but not in the CLA/C group.

\section{Percentage of individual conjugated linoleic acid in serum,} liver and epididymal white adipose tissue

The percentage of individual CLA isomers in serum and tissues of offsprings was expressed as \% of total FAME (Table 4). Both
Table 3. Body and tissue weights and serum and liver TAG content of offspring

(Mean values with their standard errors; $n 6$ animals/group)

\begin{tabular}{|c|c|c|c|c|c|c|}
\hline & \multicolumn{2}{|c|}{$\mathrm{C}^{*} / \mathrm{C}+$} & \multicolumn{2}{|c|}{$\mathrm{CLA}^{*} / \mathrm{CLA} \dagger$} & \multicolumn{2}{|c|}{$\mathrm{CLA}^{*} / \mathrm{C} \dagger$} \\
\hline & Mean & SEM & Mean & SEM & Mean & SEM \\
\hline Final BW (g) & $324 \cdot 4^{a}$ & $6 \cdot 2$ & $299 \cdot 9^{b}$ & $2 \cdot 4$ & $301 \cdot 6^{\mathrm{b}}$ & $7 \cdot 1$ \\
\hline Liver weight $(\mathrm{g})$ & $8 \cdot 19^{a}$ & 0.14 & $7.57^{\mathrm{b}}$ & 0.11 & $7 \cdot 64^{b}$ & 0.12 \\
\hline Liver weight ( $\mathrm{g} / 100 \mathrm{~g} \mathrm{BW})$ & 2.52 & 0.05 & 2.56 & 0.04 & 2.54 & 0.02 \\
\hline EWAT $(\mathrm{g})$ & $3 \cdot 48^{a}$ & 0.60 & $2 \cdot 74^{\mathrm{b}}$ & 0.06 & $2 \cdot 41^{\mathrm{b}}$ & 0.13 \\
\hline EWAT (g/100 g BW) & $1.07^{a}$ & 0.02 & $0.91^{b}$ & 0.02 & $0.80^{c}$ & 0.05 \\
\hline Serum TAG $(\mathrm{mmol} / \mathrm{l})$ & $1.06^{a}$ & 0.07 & $1.77^{\mathrm{b}}$ & 0.09 & $2 \cdot 03^{b}$ & 0.19 \\
\hline Liver TAG $(\mu \mathrm{mol} / \mathrm{g})$ & $11 \cdot 09^{a}$ & 0.45 & $8.41^{\mathrm{b}}$ & 0.75 & $11 \cdot 40^{\mathrm{a}}$ & 0.43 \\
\hline
\end{tabular}

C, control diet; CLA, conjugated linoleic acid diet; BW, body weight; EWAT, epididymal white adipose tissue.

a,b,c Mean values in the same row with unlike superscript letters were significantly different $(P<0.05)$. Statistical analyses between different groups were established by one-way ANOVA $(1 \times 3)$, followed by Scheffe's test.

* Diet fed to the dam.

$\dagger$ Diet fed to the male offspring.

Table 4. Percentage of individual conjugated linoleic acid (CLA) (\% of total fatty acids methyl esters) in serum, liver and epididymal white adipose tissue (EWAT) of offspring

(Mean values with their standard errors; $n 6$ animals/group)

\begin{tabular}{|c|c|c|c|c|c|c|}
\hline & \multicolumn{2}{|c|}{$\mathrm{C} † / C \ddagger$} & \multicolumn{2}{|c|}{ CLA†/CLA $\ddagger$} & \multicolumn{2}{|c|}{ CLA†/C } \\
\hline & Mean & SEM & Mean & SEM & Mean & SEM \\
\hline \multicolumn{7}{|l|}{ Serum } \\
\hline c9t11-CLA & $N^{a}$ & - & $0.76^{\mathrm{b} *}$ & 0.07 & $\mathrm{ND}^{\mathrm{a}}$ & - \\
\hline$t 10 c 12-C L A$ & $\mathrm{ND}^{\mathrm{a}}$ & - & $0 \cdot 12^{b}$ & 0.02 & $\mathrm{ND}^{\mathrm{a}}$ & - \\
\hline \multicolumn{7}{|l|}{ Liver } \\
\hline$c 9 t 11-C L A$ & $\mathrm{ND}^{\mathrm{a}}$ & - & $1 \cdot 12^{\mathrm{b} *}$ & 0.19 & $\mathrm{ND}^{\mathrm{a}}$ & - \\
\hline$t 10 c 12-C L A$ & $\mathrm{ND}^{\mathrm{a}}$ & - & $0.38^{b}$ & 0.13 & $\mathrm{ND}^{\mathrm{a}}$ & - \\
\hline \multicolumn{7}{|l|}{ EWAT } \\
\hline c9t11-CLA & $N D^{a}$ & - & $2 \cdot 95^{\mathrm{b} *}$ & $0 \cdot 10$ & $N D^{a}$ & - \\
\hline$t 10 c 12-C L A$ & $\mathrm{ND}^{\mathrm{a}}$ & - & $1 \cdot 39$ & $0.13^{b}$ & $\mathrm{ND}^{\mathrm{a}}$ & - \\
\hline
\end{tabular}

C, control diet; ND, not detected.

a,b Mean values in the same row with unlike superscript letters were significantly different $(P<0.05)$. Statistical analyses between different groups were established by one-way ANOVA $(1 \times 3)$, followed by Scheffe's test.

* Statistical differences between $c 9 t 11-C L A$ and $110 c 12-C L A$ isomers were established by Student's $t$ test $(P<0.05)$.

$\dagger$ Diet fed to the dam.

$\ddagger$ Diet fed to the male offspring.

CLA isomers were incorporated in serum, liver and EWAT of the CLA/CLA group, but we did not detect any CLA isomer in CLA/C rats. The percentage of individual CLA in the tissues of CLA/CLA rats was EWAT $>$ liver $>$ serum. In addition, all tissues showed higher levels of $c 9 t 11$-CLA than the $t 10 c 12$-CLA isomer.

\section{Serum and liver TAG regulation}

The serum fasting TAG levels were mainly modulated by liver TAG secretion and peripheral TAG removal (Table 5). The hepatic TAG-SR did not change in the CLA/CLA group; however, it was significantly decreased in the CLA/C group. The serum TAG removal rate was estimated by the EWAT and GM LPL activities. The EWAT LPL activity, expressed either by total tissue or by $g$ of tissue, was diminished in the CLA/CLA and CLA/C groups; however, this activity was not modified by any dietary treatment in the GM. 
Table 5. Serum and liver TAG regulation of offspring (Mean values with their standard errors; $n 6$ animals/group)

\begin{tabular}{|c|c|c|c|c|c|c|}
\hline & \multicolumn{2}{|c|}{$\mathrm{C} * \mathrm{C}+$} & \multicolumn{2}{|c|}{$\mathrm{CLA}^{*} / \mathrm{CLA} \dagger$} & \multicolumn{2}{|c|}{$\mathrm{CLA}^{*} / \mathrm{C} \dagger$} \\
\hline & Mean & SEM & Mean & SEM & Mean & SEM \\
\hline \multicolumn{7}{|l|}{ Hepatic TAG-SR } \\
\hline \multicolumn{7}{|l|}{ EWAT LPL activity } \\
\hline $\mathrm{nmol} / \mathrm{min}$ per EWAT & $958 \cdot 0^{a}$ & 89.8 & $446 \cdot 3^{\mathrm{b}}$ & 92.4 & $251 \cdot 3^{\mathrm{b}}$ & $13 \cdot 6$ \\
\hline $\mathrm{nmol} / \mathrm{min}$ per $\mu \mathrm{g}$ protein & $151 \cdot 2^{\mathrm{a}}$ & $18 \cdot 4$ & $54 \cdot 3^{\mathrm{b}}$ & 4.7 & $35 \cdot 1^{\mathrm{b}}$ & 4.6 \\
\hline \multicolumn{7}{|l|}{ GM LPL activity } \\
\hline $\mathrm{nmol} / \mathrm{min}$ per $\mathrm{GM}$ & 3.2 & 0.2 & 3.4 & 0.1 & 3.3 & 0.2 \\
\hline $\mathrm{nmol} / \mathrm{min}$ per $\mu \mathrm{g}$ protein & $46 \cdot \overline{7}$ & 3.4 & 47.4 & $2 \cdot 2$ & 43.6 & $1 \cdot 1$ \\
\hline \multicolumn{7}{|l|}{ Liver enzyme activities } \\
\hline ACC (mU/mg protein) & $84 \cdot 3^{a}$ & 3.0 & $51.0^{\mathrm{b}}$ & 2.6 & $59.0^{\mathrm{b}}$ & $6 \cdot 1$ \\
\hline FAS (mU/mg protein) & $5 \cdot 2^{a}$ & 0.4 & $3 \cdot 3^{\mathrm{b}}$ & 0.2 & $3.3^{\mathrm{b}}$ & 0.2 \\
\hline G6PDH (mU/mg protein) & $54 \cdot 1^{\mathrm{a}}$ & 4.0 & $36 \cdot 3^{\mathrm{b}}$ & 2.6 & $21 \cdot 6^{\mathrm{C}}$ & 1.6 \\
\hline CPT-la (mU/mg protein) & 1.8 & 0.2 & 1.5 & 0.1 & 1.7 & 0.2 \\
\hline
\end{tabular}

C, control diet; CLA, conjugated linoleic acid diet; TAG-SR, TAG secretion rate; EWAT, epididymal white adipose tissue; GM, gastrocnemius muscle; LPL, lipoprotein lipase; ACC, acetyl-CoA carboxylase; FAS, fatty acid synthase; G6PDH, glucose-6phosphate dehydrogenase; CPT-la, carnitine palmitoyltranferase-la; $1 \mathrm{mU}, 1 \mathrm{nmo}$ $\mathrm{NADH}$ consumed/min (ACC); $1 \mathrm{nmol} \mathrm{NADPH}$ consumed/min (FAS); $1 \mathrm{nmol}$ NADPH produced per min (G6PDH); $1 \mathrm{nmol} \mathrm{CoA} / \mathrm{min}$ (CPT-la).

a,b,c Mean values in the same row with unlike superscript letters were significantly different $(P<0.05)$. Statistical analyses between different groups were established by one-way ANOVA $(1 \times 3)$, followed by Scheffe's test.

* Diet fed to the dam.

† Diet fed to the male offspring.

Table 6. Hepatic mRNA levels of lipogenic and $\beta$-oxidative enzymes, transcriptional factors and inflammatory cytokines of offspring

(Mean values with their standard errors; $n 6$ animals/group (relative units))

\begin{tabular}{|c|c|c|c|c|c|c|}
\hline & \multicolumn{2}{|c|}{$\mathrm{C}^{*} / \mathrm{C} \dagger$} & \multicolumn{2}{|c|}{$\mathrm{CLA}^{*} / \mathrm{CLA} \dagger$} & \multicolumn{2}{|c|}{$\mathrm{CLA}^{*} / \mathrm{C} \dagger$} \\
\hline & Mean & SEM & Mean & SEM & Mean & SEM \\
\hline $\mathrm{ACC}$ & $1.000^{\mathrm{a}}$ & 0.033 & $0.551^{b}$ & 0.097 & $0.446^{\mathrm{b}}$ & 0.049 \\
\hline FAS & $1.000^{\mathrm{a}}$ & 0.062 & $0.502^{\mathrm{b}}$ & 0.096 & $0.936^{a}$ & 0.065 \\
\hline SCD-1 & $1.000^{\mathrm{a}}$ & 0.020 & $0.325^{\mathrm{b}}$ & 0.100 & $0.656^{c}$ & 0.042 \\
\hline SREBP-1C & $1.000^{\mathrm{a}}$ & 0.021 & $0.643^{\mathrm{b}}$ & 0.152 & $1.206^{\mathrm{a}}$ & 0.030 \\
\hline CPT-Іа & $1.000^{\mathrm{a}}$ & 0.025 & $0.881^{a}$ & 0.063 & $0.509^{b}$ & 0.029 \\
\hline PPAR $a$ & $1.000^{\mathrm{a}}$ & 0.018 & $1.050^{\mathrm{a}}$ & 0.065 & $0.733^{\mathrm{b}}$ & 0.020 \\
\hline IL-6 & 1.000 & 0.250 & 0.823 & 0.099 & 1.025 & 0.156 \\
\hline $\mathrm{IL}-1 \beta$ & $1.000^{\mathrm{a}}$ & 0.056 & $0.613^{b}$ & 0.041 & $0.666^{\mathrm{b}}$ & 0.060 \\
\hline PPARY & $1.000^{\mathrm{a}}$ & 0.032 & $0.716^{\mathrm{b}}$ & 0.049 & $0.559^{b}$ & 0.014 \\
\hline
\end{tabular}

C, control diet; CLA, conjugated linoleic acid diet; ACC, acetyl-CoA carboxylase; FAS, fatty acid synthase; SCD-1, stearoyl-CoA desaturase-1; SREBP-1c, sterol regulatory element-binding protein 1c, CPT-la, carnitine palmitoyltransferase la.

a,b Mean values in the same row with unlike superscript letters were significantly different $(P<0.05)$. Statistical analyses between different groups were established

by one-way ANOVA $(1 \times 3)$, followed by Scheffe's test.

* Diet fed to the dam.

$\dagger$ Diet fed to the male offspring.

The fasting hepatic TAG levels were mostly regulated by lipogenesis, $\beta$-oxidation and hepatic TAG-SR (Table 5). The ACC, FAS and G6PDH activities were diminished in the CLA/ CLA and CLA/C groups. Meanwhile, the activity of the main enzyme involved in the hepatic FA oxidation, CPT-Ia, was not modified in the CLA/CLA and CLA/C groups.

The liver expression of some key genes and transcriptional factors related to FA biosynthesis (Acc, Fas, Scd1 and Srebpf1c) and $\beta$-oxidation (Cpt1a, Ppara), as well as inflammation (Il6, Il1b, Pparg), are shown in Table 6. The levels of mRNA of ACC,
FAS, SCD-1a and SREBP-1c were diminished in the CLA/CLA group. The ACC, but not FAS, SCD-1 and SREBP-1c, gene expression was decreased in the CLA/C group. As regards fatty acid oxidation, CPT-Ia and PPAR $\alpha$ mRNA levels were unchanged in CLA/CLA group, but decreased in the CLA/C group. In addition, some of the genes related to inflammation were assayed, showing a significant decrease in the Pparg and $I l 1 b$ expression in both CLA/CLA and CLA/C. No changes were observed in IL-6 mRNA levels.

\section{Discussion}

Dietary CLA reduces body fat accumulation and modulates lipid metabolism, as well as the inflammatory response, which could have a potential key role during the gestation period. The CLAmix oil contains mainly $c 9 t 11$-CLA and $t 10 c 12$-CLA in equimolecular proportion; however, their biological effects are different. Even though both isomers are involved in lipid metabolism regulation, $t 10 c 12$-CLA is principally responsible for increasing lipolysis and the $\beta$-oxidation/lipogenesis ratio modulating fat accretion $^{(7)}$, whereas the $c 9 t 11$-CLA has an anti-inflammatory response ${ }^{(36)}$. Taking into account that the reduction in lipid depots might induce metabolic changes in the offspring, increasing the risk of metabolic alteration in adult life ${ }^{(13)}$, the aim of this study was to investigate the effect of maternal CLA consumption on nutritional parameters, TAG levels in serum and liver, as well as their regulation in adult offspring rats that received CLA or not. In addition, some gene expression factors related to the inflammatory process were studied. To the best of our knowledge, this is the first study to investigate the influence of maternal CLA on TAG metabolism in adult offspring rats fed normo-energetic diets.

It is known that CLA reduces the fat mass by different mechanisms including decreased fatty acid uptake, increased fatty acid oxidation, increased overall energy expenditure and others $^{(1)}$. In agreement with several studies in different experimental animal models fed CLA ${ }^{(8,34,37)}$, the present results in offspring male rats fed CLA (CLA/CLA group) showed a lower final body weight related to reduced fat depots. It is important to note that the results on rat body composition are controversial, depending on the type of isomer and level of CLA, nutritional status and time of feeding ${ }^{(3,8)}$. There are few studies showing the effect of CLA on adult offspring rats fed the same diet as the dams. In a previous study from our laboratory ${ }^{(17)}$, CLA reduced the EWAT weights at first and second generation of mice, and similar results have been obtained in rats of the first generation ${ }^{(14)}$. In the present study, the effects on fat depots were observed in the presence of high CLA levels in adipose tissue (CLA/CLA group) and in the absence of CLA (CLA/C group). It is well known that CLA isomers are incorporated and metabolised into the tissues, and the rate of CLA metabolism is sensitive to experimental conditions ${ }^{(38)}$. However, to the best of our knowledge, there is no study showing the disappearance rate of CLA in the offspring of CLA-fed mothers; therefore, the measurement of CLA levels in tissues of the CLA/C group was performed to warrant the absence of CLA in tissues of offspring. Thus, the metabolic effects of the diets in the offspring could be specifically attributed to maternal CLA, which was administered 
to the dams during pregnancy and lactation. Interestingly, those adult offspring from CLA-fed rats that were fed $\mathrm{C}$ diets after weaning (CLA/C group) also showed a reduction of body and EWAT weights. It is noteworthy that in both offspring from CLA dams the reduction of EWAT was associated with a lower LPL enzyme activity. These results might hypothesise that a programming mechanism of CLA during early life could be involved in controlling the adiposity in offspring through the fatty acid uptake by the EWAT.

The plasma TAG levels were regulated by the circulating TAG removal rate from the adipose tissue and muscle, as well as by the hepatic VLDL-TAG secretion. As the hepatic VLDLTAG-SR was not increased and the muscle LPL enzyme activity did not change by the dietary treatments, the reduced LPL activity in EWAT could explain the higher plasma TAG levels in both CLA/C and CLA/CLA groups. A similar association between the increase of plasma TAG and the reduction of adipose tissue LPL activity was found in mice fed different types of oils supplemented with $1 \%$ CLA-mix oil at normal fat levels ${ }^{(39)}$ and hamsters fed high-fat diets supplemented with a similar commercial CLA ${ }^{(40)}$. However, compared with results previously observed in mice ${ }^{(39)}$, in the present work, the VLDLTAG-SR did not contribute to the hypertriacylglycerolaemia. Other authors found a reduction in mice fed high-fat diets ${ }^{(34,41)}$ or no changes in serum TAG in rats fed diets rich in saturated fats ${ }^{(42)}$. Thus, the differences observed in the effect of CLA-mix oil are not only owing to the species but also to the type of isomer and dietary experimental protocol, among other reasons.

Liver is an organ that plays a crucial role in lipid metabolism and has been reported to be a key target for CLA ${ }^{(1)}$. As shown in EWAT, CLA was incorporated into the liver of CLA/CLA, but was not detected in the CLA/C group. In the CLA/CLA group, the percentage of $c 9 t 11$-CLA was higher than that of the $110, \mathrm{c} 12$ CLA isomer. Similar results have been previously shown in animals fed CLA diets ${ }^{(43)}$. The effect of CLA on hepatic TAG has been proposed to be species specific ${ }^{(44)}$. In contrast to the effects described by CLA inducing a significant liver TAG accretion in mice $^{(7,34)}$, neither liver steatosis nor hepatomegaly was observed in both groups of offspring rats from CLA-fed dams. Furthermore, CLA/CLA rats showed a reduction of hepatic TAG content. The lowering effect of CLA on hepatic TAG has been previously shown in rats under different conditions of liver steatosis ${ }^{(43,45-49)}$. Purushotham et al. ${ }^{(43)}$ proposed that CLA attenuated hepatic steatosis in adult Wistar rats by modulating hepatic genes involved in lipogenesis and lipid oxidation. In addition, these authors suggested that the dissimilar effects of CLA on hepatic steatosis and insulin sensitivity may depend on differences in fat-to-lean partitioning between adipose and liver tissues in numerous animal models. Interestingly, in both groups of rats from CLA-fed dams, the lipogenesis was significantly reduced. Specifically, in the CLA/CLA group, the lower ACC, FAS and G6PDH activities and reduced mRNA levels of ACC, FAS, SCD-1 and SREBP-1c, with normal CPT-Ia activity and mRNA levels clearly demonstrated an unbalance between lipogenesis and $\beta$-oxidation. In agreement with our results, CLA decreased the hepatic FAS ${ }^{(50)}$ and SCD- ${ }^{(51)}$ activities and FAS ${ }^{(52)}$ and SCD-1 ${ }^{(51,52)}$ mRNA levels. In addition, an unchanged FA oxidation has also been observed ${ }^{(53)}$. However, some reports have shown increased ${ }^{(54,55)}$ and reduced ${ }^{(56)}$ FA oxidation. A reduced lipogenesis was also observed in the CLA/ $\mathrm{C}$ group, but in contrast to the CLA/CLA group two different compensatory mechanisms might be involved to balance the hepatic TAG levels. Specifically, a decreased $\beta$-oxidation, as a result of a lower CPT-1a gene expression, and a reduction of hepatic TAG secretion contributed to maintain the normal hepatic TAG content. The most interesting and original result is that a lower ACC, FAS and G6PDH enzyme activity and a diminished mRNA level of ACC was also observed even in the absence of CLA in the diet. Reinforcing the above-mentioned effects observed in body composition, CLA might programme the lipid metabolism driving to a prevention of liver TAG accretion. There are no studies reporting data to contrast with the present findings.

The beneficial effects of CLA on immune and inflammatory responses in different animal models, describing the mechanism of action of CLA, particularly the c9,t11-18:2, have recently been reviewed ${ }^{(57)}$. Thus, after CLA exposure, a reduction of pro-inflammatory cytokine production has been described, mainly IL-6, TNF $\alpha$, IFN $\gamma$, and IL- $1 \beta$, which could play an important role in the pathogenesis of many chronicinflammation-mediated diseases ${ }^{(58,59)}$. Reynolds et $a l^{(14)}$ and Segovia et al. ${ }^{(15)}$ demonstrated in different experimental animal models that CLA reversed maternal metainflammation induced by high-fat diet and prevented programming of adverse offspring metabolic outcomes. Our results also show that CLA might down-regulate the liver gene expression of some proinflammatory factors such as IL- $1 \beta$ and PPAR $\gamma$ in offspring, even at recommended dietary fat levels.

In brief, these results demonstrate a programming effect of CLA on lipid metabolic pathways leading to a preventive effect on the TAG accretion in adipose tissue and liver of male rat offspring. This knowledge could be important to develop some dietary strategies to reduce the incidence of obesity and fatty acid liver disease in humans.

\section{Acknowledgements}

The authors wish to thank Walter DaRú for his technical assistance.

This study was supported by Universidad Nacional del Litoral-Cursos de Acción para la Investigación y el Desarrollo (CAI+D 2011 nos 50120110100165 LI and 50120110100166 LI)-Secretaría de Ciencia y Técnica-UNL and Consejo Nacional de Investigaciones Científicas y Técnicas (PIP CONICET no. 112-200801-00786).

C. A. B. designed and planned the study, as well as analysed results, interpreted findings and wrote the manuscript; J. V. L. conducted the study, performed the sample analysis, analysed the data, interpreted findings and prepared the manuscript; C. D. G., J. S. and A. C. F. carried out collections and analytical determinations and assisted in the maintenance and killing of rats; M. A. G. contributed to the design and planning of the study, interpreted findings and discussed the manuscript. 


\section{References}

1. Pariza MW, Park Y \& Cook ME (2001) The biologically active isomers of conjugated linoleic acid. Prog Lipid Res $\mathbf{4 0}$, 283-298.

2. Kelley DS, Bartolini GL, Newman JW, et al. (2006) Fatty acid composition of liver, adipose tissue, spleen, and heart of mice fed diets containing t10, c12-, and c9, t11-conjugated linoleic acid. Prostaglandins Leukot Essent Fatty Acids $\mathbf{7 4}$, 331-338.

3. Bhattacharya A, Banu J, Rahman M, et al. (2006) Biological effects of conjugated linoleic acids in health and disease. J Nutr Biochem 17, 789-810.

4. Kim HK, Kim SR, Ahn JY, et al. (2005) Dietary conjugated linoleic acid reduces lipid peroxidation by increasing oxidative stability in rats. J Nutr Sci Vitaminol 51, 8-15.

5. Nagao K, Inoue N, Wang YM, et al. (2005) Dietary conjugated linoleic acid alleviates nonalcoholic fatty liver disease in Zucker (fa/fa) rats. J Nutr 135, 9-13.

6. Andreoli MF, Scalerandi MV, Borel IM, et al. (2007) Effects of CLA at different dietary fat levels on the nutritional status of rats during protein repletion. Nutrition 23, 827-835.

7. Poirier H, Niot I, Clement L, et al. (2005) Development of conjugated linoleic acid (CLA)-mediated lipoatrophic syndrome in the mouse. Biochimie 87, 73-79.

8. Park Y \& Pariza MW (2007) Mechanisms of body fat modulation by conjugated linoleic acid (CLA). Food Res Int $\mathbf{4 0}$, 311-323.

9. Bursztyn M \& Ariel I (2006) Maternal-fetal deprivation and the cardiometabolic syndrome. I Cardiometab Syndr $\mathbf{1}$, 141-145.

10. Li X, Yang J, Zhu Y, et al. (2017) Mouse maternal high-fat intake dynamically programmed mRNA $\mathrm{m}^{6} \mathrm{~A}$ modifications in adipose and skeletal muscle tissues in offspring. Int J Mol Sci 17, 1336.

11. Oliveira L, Souza LL, Souza AFP, et al. (2016) Perinatal maternal high-fat diet promotes alterations in hepatic lipid metabolism and resistance to the hypolipidemic effect of fish oil in adolescent rat offspring. Mol Nutr Food Res 60, 2493-2504.

12. Yokomizo $\mathrm{H}$, Inoguchi $\mathrm{T}$, Sonoda $\mathrm{N}$, et al. (2014) Maternal high-fat diet induces insulin resistance and deterioration of pancreatic cell function in adult offspring with sex differences in mice. Am J Physiol Endocrinol Metab 306, E1163-E1175.

13. Herrera E, López-Soldado I, Limones M, et al. (2005) Experimental models for studying perinatal lipid metabolism. Longterm effects of perinatal undernutrition. Adv Exp Med Biol 569, 95-108.

14. Reynolds CM, Segovia SA, Zhang XD, et al. (2015) Conjugated linoleic acid supplementation during pregnancy and lactation reduces maternal high-fat-diet-induced programming of earlyonset puberty and hyperlipidemia in female rat offspring. Biol Reprod 92, 1-10.

15. Segovia SA, Vickers MH, Zhang XD, et al. (2015) Maternal supplementation with conjugated linoleic acid in the setting of diet-induced obesity normalises the inflammatory phenotype in mothers and reverses metabolic dysfunction and impaired insulin sensitivity in offspring. J Nutr Biochem 26, 1448-1157.

16. Pileggi CA, Segovia SA, Markworth JF, et al. (2016) Maternal conjugated linoleic acid supplementation reverses high-fat diet-induced skeletal muscle atrophy and inflammation in adult male rat offspring. Am J Physiol Regul Integr Comp Physiol 310, R432-R439.

17. Veaute C, Andreoli MF, Racca A, et al. (2007) Effects of isomeric fatty acids on reproductive parameters in mice. $\mathrm{Am}$ J Reprod immunol 58, 487-496.
18. Reeves PG, Nielsen FH \& Fahey GC Jr (1993) AIN-93 purified diets for laboratory rodents: final report of the American Institute of Nutrition ad hoc writing committee on the reformulation of the AIN-76A rodent diet. J Nutr 123, 1939-1951.

19. Bayne K (1996) Revised guide for the care and use of laboratory animals available. American Physiological Society. Physiologist 39, 208-211.

20. Bligh EG \& Dyer WJ (1959) A rapid method of total lipid extraction and purification. Can J Biochem Physiol 37, 911-917.

21. Saín J, Gonzalez MA, Lavandera JV, et al. (2015) Scalerandi MV, Bernal CA. Trans fatty acid retention and conversion rates of fatty acids in tissues depend on dietary fat in mice. Eur J Lipid Sci Technol 117, 1146-1158.

22. Fariña AC, González MA, Scalerandi MV, et al. (2015) Nutritional and metabolic effects of dietary trans fats depend on the intake of linoleic acid. Eur J Lipid Sci Technol 117, 933-944.

23. Laurell S (1966) A method for routine determination of plasma triglycerides. Scand J Clin Lab Invest 18, 668-672.

24. Del Prado M, Hernandez-Montes H \& Villalpando S (1994) Characterization of a fluorometric method for lipoprotein lipase. Arch Med Res 25, 331-335.

25. Zimmerman R (2003) Decreased fatty acid esterification compensates for the reduced lipolytic activity in hormonesensitive lipase-deficient white adipose tissue. J Lipid Res $\mathbf{4 4}$, 2089-2099.

26. Lynen F (1969) Yeast fatty acid synthase. Methods Enzym 14, $14-17$.

27. Kuby SA \& Noltmann EA (1966) Glucose 6-phosphate dehydrogenase from brewers yeast. Methods Enzym 9, 116-117.

28. Bieber LL, Abraham T \& Helmrath T (1972) A rapid spectrophometric assay for carnitine palmitoyltransferase. Anal Biochem 50, 509-518.

29. Lowry OH, Rosebrough NJ, Farr AL, et al. (1951) Protein measurement with the Folin phenol 22 reagent. J Biol Chem 193, 265-275.

30. Rasmussen R (2001) Quantification on the LightCycler. In Rapid Cycle Real-time PCR, Methods and Applications, pp. 21-34 [S Meuer, C Wittwer and K Nakagawara, editors]. Heidelberg: Springer Press.

31. Vandesompele J, De Preter K, Pattyn F, et al. (2002) Accurate normalization of real-time quantitative RT-PCR data by geometric averaging of multiple internal control genes. Genome Biol 3, research0034.1-0034.11.

32. Livak KJ, Schmit TA \& Gen TD (2001) Analysis of relative gene expression data using real-time quantitative PCR and the 2(-Delta Delta C(T)) method. Methods 25, 402-408.

33. Otway S \& Robinson DS (1967) The use of a non-ionic detergent (Triton WR 1339) to determine rates of triglyceride entry into the circulation of the rat under different physiological conditions. J Physiol 190, 321-332.

34. Andreoli MF, Gonzalez MA, Martinelli MI, et al. (2009) Effects of dietary conjugated linoleic acid at high-fat levels on triacylglycerol regulation in mice. Nutrition 25, 445-452.

35. Bowker AH \& Lieberman GJ (1972) Engineering Statistics, 2nd ed. Prentice Hall, NJ: Englewood Cliffs.

36. Wang J, Liu X, Zhang X, et al. (2013) Induction of apoptosis by c9, t11-CLA in human endometrial cancer RL 95-2 cells via ERo-mediated pathway. Chem Phys Lipids 175-176, 27-32.

37. Ryder JW, Portocarrero CP, Song XM, et al. (2001) Isomerspecific antidiabetic properties of conjugated linoleic acid. Improved glucose tolerance, skeletal muscle insulin action, and UCP-2 gene expression. Diabetes 50, 1149-1157.

38. Banni S (2002) Conjugated linoleic acid metabolism. Curr Opin Lipidol 13, 261-266. 
39. Scalerandi MV, Gonzalez MA, Saín J, et al. (2014) Effect of conjugated linoleic acid mixtures and different edible oils in body composition and lipid regulation in mice. Nutr Hosp $\mathbf{2 9}$, 591-601.

40. Deckere EAM, van Amelsvoort JMM, McNeill GP, et al. (1999) Effects of conjugated linoleic acid (CLA) isomers on lipid levels and peroxisome proliferation in the hamster. Br J Nut 82, 309-317.

41. Liu LF, Purushotham A, Wendel AA, et al. (2007) Combined effects of rosiglitazone and conjugated linoleic acid on adiposity, insulin sensitivity, and hepatic steatosis in high-fat-fed mice. Am J Physiol Gastrointest Liver Physiol 292, G1671-G1682.

42. Kloss R, Linscheid J, Johnson A, et al. (2005) Effects of conjugated linoleic acid supplementation on blood lipids and adiposity of rats fed diets rich in saturated versus unsaturated fat. Pharmacol Res 51, 503-507.

43. Purushotham A, Shrode G, Wendel A, et al. (2007) Conjugated linoleic acid does not reduce body fat but decreases hepatic steatosis in adult Wistar rats. J Nutr Biochem 18, 676-684

44. Vyas D, Kadegowda AK \& Erdman RA (2012) Dietary conjugated linoleic acid and hepatic steatosis: species-specific effects on liver and adipose lipid metabolism and gene expression. J Nutr Metab 2012, 932928.

45. Andreoli MF, Illesca PG, González MA, et al. (2010) Conjugated linoleic acid reduces hepatic steatosis and restores liver triacylglycerol secretion and the fatty acid profile during protein repletion in rats. Lipids 45, 1035-1045.

46. Sébédio JL, Angioni E, Chardigny JM, et al. (2001) The effect of conjugated linoleic acid isomers on fatty acid profiles of liver and adipose tissues and their conversion to isomers of 16:2 and 18:3 conjugated fatty acids in rats. Lipids 36, 575-582.

47. Nagao K, Inoue N, Wang YM, et al. (2005) Dietary conjugated linoleic acid alleviates nonalcoholic fatty liver disease in Zucker (fa/fa) rats. J Nutr 135, 9-13.

48. Rahman SM, Huda MN, Uddin MN, et al. (2002) Short-term administration of conjugated linoleic acid reduces liver triglyceride concentration and phosphatidate phosphohydrolase activity in OLETF rats. J Biochem Mol Biol 35, 494-497.
49. Wang $\mathrm{YM}$, Nagao K, Inoue $\mathrm{N}$, et al. (2006) Isomer-specific anti-obese and hypolipidemic properties of conjugated linoleic acid in obese OLETF rats. Biosci Biotechnol Biochem 70, 355-362.

50. Azain MJ, Hausman DB, Sisk MB, et al. (2000) Dietary conjugated linoleic acid reduces rat adipose tissue cell size rather than cell number. J Nutr 130, 1548-1554.

51. Choi Y, Park Y, Pariza MW, et al. (2001) Regulation of stearoyl-CoA desaturase activity by the trans-10,cis-12 isomer of conjugated linoleic acid in HepG2 cells. Biochem Biophys Res Commun 284, 689-693.

52. Maslak E, Buczek E, Szumny A, et al. (2015) Individual CLA isomers, c9t11 and t10c12, prevent excess liver glycogen storage and inhibit lipogenic genes expression induced by high-fructose diet in rats. BioMed Res Int 2015, 535982.

53. Park Y, Albright KJ, Liu W, et al. (1997) Effect of conjugated linoleic acid on body composition in mice. Lipids 32, $853-858$.

54. Ide T (2005) Interaction of fish oil and conjugated linoleic acid in affecting hepatic activity of lipogenic enzymes and gene expression in liver and adipose tissue. Diabetes 54, 412-423.

55. Degrace P, Demizieux L, Gresti J, et al. (2004) Hepatic steatosis is not due to impaired fatty acid oxidation capacities in C57BL/6J mice fed the conjugated trans-10,cis-12-isomer of linoleic acid. $J$ Nutr 134, 861-867.

56. Rasooly R, Kelley DS, Greg J, et al. (2007) Dietary trans 10, cis 12-conjugated linoleic acid reduces the expression of fatty acid oxidation and drug detoxification enzymes in mouse liver. Br J Nutr 97, 58-66.

57. Viladomiu M, Hontecillas R \& Bassaganya-Riera J (2016) Modulation of inflammation and immunity by dietary conjugated linoleic acid. Eur J Pharmacol 785, 87-95.

58. O'Shea M, Bassaganya-Riera J \& Mohede IC (2004) Immunomodulatory properties of conjugated linoleicacid. Am J Clin Nutr 79, 1199S-1206S.

59. Bassaganya-Riera J \& Hontecillas R (2010) Dietary conjugated linoleic acid and n-3 polyunsaturated fatty acids in inflammatory bowel disease. Curr Opin Clin Nutr Metab Care 13, $569-573$. 